\title{
OS APORTES NORMATIVOS RELATIVOS AOS TERRITÓRIOS QUILOMBOLAS: UMA LEITURA A PARTIR DO NOVO CONSTITUCIONALISMO LATINO AMERICANO
}

Les apports normatives sur les territoires quilombolas: une lecture à partir du nouveau constitutionnalisme latino-américaine

Maria Cristina Vidotte Blanco Tarrega ${ }^{1}$ Rangel Donizete Franco ${ }^{2}$

\begin{tabular}{|c|c|}
\hline RESUMO & RÉSUMÉ \\
\hline $\begin{array}{l}\text { O artigo tem por objeto a explicitação dos referenciais } \\
\text { normativos sobre a regularizaça dos territórios } \\
\text { quilombolas no Brasil, na perspectiva do Novo } \\
\text { Constitucionalismo Latino Americano. Incialmente, } \\
\text { são apresentadas as características da perspectiva } \\
\text { teórica adotada. Após, são descritas a Convenção } \\
\text { Americana de Direitos Humanos e a Convenção sobre } \\
\text { os Povos Indígenas e Tribais da OIT. Em seguida, é } \\
\text { apresentada a regulamentação interna sobre a questão } \\
\text { territorial quilombola, desde as primeiras portarias até } \\
\text { o Decreto n. }{ }^{\circ} \text { 4.887/03, que atualmente fixa o } \\
\text { procedimento para a regularização dos territórios } \\
\text { quilombolas no Brasil. Por fim, apresenta-se o } \\
\text { Programa Brasil Quilombola, a partir de seus } \\
\text { principais eixos, como política pública que sustenta a } \\
\text { perspectiva de concretização dos direitos territoriais } \\
\text { dos quilombolas. }\end{array}$ & $\begin{array}{l}\text { L'article se concentre sur l'explicitation des cadres } \\
\text { juridiques sur le règlement des territoires quilombolas } \\
\text { au Brésil, du point de vue du nouveau } \\
\text { constitutionnalisme latino-américaine. Au départ, sont } \\
\text { presentés les caractéristiques de la perspective } \\
\text { théorique adoptée. Aprés, sont décrits la Convention } \\
\text { américaine relative aux droits de l'homme et la } \\
\text { Convention relative aux peuples indigènes et tribaux } \\
\text { de l'OIT. Dans la section qui suit, présente les règles } \\
\text { internes sur la question territoriale quilombola, dès les } \\
\text { premières ordonnances jusqu'à ce que le décret n. } \\
\text { 4.887/03, qui définit actuellement la procédure pour le } \\
\text { règlement des territoires quilombolas au Brésil. Enfin, } \\
\text { présente le programme Brésil Quilombola, à partir de } \\
\text { ses axes principaux, en tant que politique publique qui } \\
\text { appuie le point de vue de concrétion des droits } \\
\text { territoriaux des quilombolas. }\end{array}$ \\
\hline $\begin{array}{l}\text { Palavras-chave: Direito agrário. Regularização. } \\
\text { Território Quilombola. Normatividade. }\end{array}$ & $\begin{array}{l}\text { Mots-Clés: Droit agraire. Régularisation. Territoire } \\
\text { Quilombola. Normativité. }\end{array}$ \\
\hline
\end{tabular}

\section{INTRODUÇÃO}

O objetivo deste artigo é explicitar as principais referências normativas, tanto internas quanto externas, que fundamentam atualmente a discussão jurídica sobre a regularização dos territórios ocupados por comunidades remanescentes de quilombos no Brasil. A proposta é

\footnotetext{
1 Doutora em Direito pela PUC-SP. Professora Titular da Universidade Federal de Goiás (UFG). Subcoordenadora do Programa de Mestrado em Direito Agrário da UFG. Email: mcvidotte@uol.com.br.

2 Mestre em Direito Agrário pela UFG. Professor da Faculdade Sul-Americana (Fasam). Email: rangeldonizetefranco@gmail.com
} 
86

tentar compreender, num exercício hermenêutico, essas referências normativas na perspectiva teórica do Novo Constitucionalismo Latino Americano.

A matéria é relevante porque permite refletir sobre a distância abissal que separa a normatividade do real na questão de apropriação territorial pelos quilombolas. Segundo dados da Coordenação-Geral de Territórios Quilombolas do INCRA “[...] na atualidade existem 120 títulos emitidos, regularizando 987.935,9873 hectares em benefício de 108 territórios, 189 comunidades e 11.918 famílias quilombolas [...]” (INCRA, 2011). Já segundo a Fundação Cultural Palmares existem mais de três mil e quinhentas comunidades quilombolas identificadas no território nacional, sendo que 1.820 foram certificadas (FCP, 2012).

Comparando o dado do INCRA, que indica a existência de 120 títulos emitidos, e o dado da FCP, que aponta para existência de 3.524 comunidades quilombolas no Brasil, notase claramente que muito pouco foi feito em termos de titulação efetiva dos territórios quilombolas.

Esse contraste é referido por Almeida (2008, p. 119), quando escreve que "[...] as terras de quilombos, estima-se oficialmente que correspondam a mais de 30 milhões de hectares. Em contraste as terras de quilombos tituladas correspondem a cerca de 900 mil hectares $[\ldots] "$ ".

A relevância do tema também está evidenciada pela iminência de julgamento, pelo Supremo Tribunal Federal, da Ação Direta de Inconstitucionalidade n. ${ }^{\circ}$ 3.239/DF ${ }^{3}$. Sem esquecer, por evidente, a vinculação da temática com a efetivação da cidadania em benefício de grupos étnico historicamente excluído do acesso aos benefícios sociais: os quilombolas.

O ponto de partida da reflexão é a premissa de que a questão das terras de quilombos é parte da questão agrária brasileira, que ainda não foi resolvida.

\footnotetext{
${ }^{3}$ Essa Ação Direta de Inconstitucionalidade (ADI 3.239/DF), cujo relator é o Min. Cezar Peluso, foi proposta em 25 de junho de 2004 pelo Partido da Frente Liberal (PFL) - atual DEM (Democratas) -, tendo por objeto a declaração de inconstitucionalidade do Decreto n. ${ }^{\circ}$ 4.887, de 20 de novembro de 2003, que regulamenta o procedimento para identificação, reconhecimento, delimitação, demarcação e titulação das terras ocupadas remanescentes das comunidades dos quilombos, sob o fundamento de que ele invade matéria reservada à lei pela Constituição Federal, que prevê desapropriação onde não cabe, que o critério da auto-definição é inconstitucional. Disponível em: <http://redir.stf.jus.br/estfvisualizadorpub/jsp/consultarprocessoeletronico/>. Acesso em: 20 maio 2012.
} 


\section{O Novo Constitucionalismo Latino Americano}

Em termos terminológicos, alguns autores (VICIANO PASTOR, 2011; DALMAU, 2009) valem-se do termo "novo constitucionalismo latino-americano", ${ }_{4}^{4}$ outros falam de “constitucionalismo pluralista” (APARÍCIO WILHELMI, 2010).

Viciano Pastor (2011), discutindo como é a regulamentação do direito de propriedade da terra nas Constituições da Colômbia, da Venezuela, do Equador e da Bolívia, refere que elas são emblemáticas do Novo Constitucionalismo Latino-Americano, cujo marco geográfico é a América Latina e o temporal, ao menos inicial, a Constituição Colombiana de $1991 .^{5}$

Martínez Dalmau, ${ }^{6}$ em entrevista à Folha de São Paulo, afirma que o novo constitucionalismo democrático latino-americano

Trata-se, recolhendo a evolução do constitucionalismo desde a sua aparição, no século 18 , e em particular os avanços no constitucionalismo europeu depois da Segunda Guerra Mundial, de avançar em âmbitos nos quais o constitucionalismo europeu ficou paralisado: a democracia participativa, a vigência dos direitos sociais e dos demais direitos, a busca de um novo papel da sociedade no Estado e a integração das minorias até agora marginalizadas.

Da citação imediatamente acima, dois aspectos justificam a invocação do novo constitucionalismo latino americano como base teórica do trabalho. São a valorização da ideia de vigência dos direitos sociais, dado que o direito ao território das comunidades quilombolas insere-se entre eles, merecendo pronta e eficaz concretização, seja pelos poderes estatais, econômicos e particulares, e a perspectiva de integração das minorias, cujo um dos

\footnotetext{
${ }^{4}$ Para uma discussão do Novo Constitucionalismo Democrático Latino Americano como paradigma jurídico num contexto de crise paradigmática, ver Freitas (2012).

${ }^{5}$ Segundo Viciano Pastor (2011), são notas características desse novo constitucionalismo, entre outras: a existência de uma assembleia constituinte baseada na democracia participativa, a contemplação mais ampla de direitos individuais e coletivos e o reconhecimento do pluralismo jurídico. Essas informações foram anotadas por ocasião da palestra do Professor Roberto Alfonso Viciano Pastor, intitulada "El derecho de propriedade y la propriedad de la tierra en el Nuevo Constitucionalismo Latinoamericano", em Goiânia, no dia 31 de agosto de 2011, no I Congresso Internacional sobre o Pensamento Jurídico Contemporâneo e XV Jornada Goiana de Filosofia e Teoria do Direito, intitulado "Propriedade e Desenvolvimento: seus direitos e seus sujeitos", realizado entre os dias 30 de agosto e 02 de setembro de 2011, na Faculdade de Direito da Universidade Federal de Goiás.

6 Disponível em: <http://supremoemdebate.blogspot.com/2009/03/novo-constitucionalismo-latino.html.>. Acesso em 16 out. 2011.
} 
exemplos mais notórios no país são as comunidades quilombolas, em regra, esquecidas dos poderes e até de estudos acadêmicos.

Segundo Vieira (2009, p. 15-16), as dez características desse Novo Constitucionalismo Latino-Americano são:

- Tem seu marco inicial com a promulgação da Constituição Venezuelana de 1999. Deu origem, também, às atuais constituições do Equador (2008) e da Bolívia (2009).

- O texto constitucional é elaborado por uma assembleia constituinte participativa, sendo posteriormente submetido à aprovação popular (referéndums aprobatorios).

-.Produz constituições extensas (Venezuela: 350 artigos, Bolívia: 411 artigos, Equador: 444 artigos), adaptadas a realidade de cada país, de acordo com seus próprios marcos históricoculturais. A título de comparação, a Constituição Brasileira de 1988 tem 250 artigos.

-.Parte do constitucionalismo clássico de matriz europeia, procurando superá-lo no que este não avançou. Para tanto, promove a recuperação e releitura da categoria "soberania popular", no sentido de refundar o Estado, promovendo a participação direta do povo na elaboração e aprovação da constituição, bem como no controle e gestão da administração.

-.Estabelece instituições paralelas de controle baseadas na participação popular: "Poder Cidadão" (Venezuela), "Controle Social" (Bolívia) e o "Quinto Poder" (como ficou conhecido no Equador).

-.Compreende o povo como uma comunidade aberta de sujeitos constituintes que entre si "contratualizam", "pactuam" e consentem o modo de governo do Estado.

- Revela o fenômeno da "Globalização", que une o global ao local, em um processo que conjuga a integração internacional e o redescobrimento de valores, tradições e de estruturas locais e particulares.

-.Procura promover um novo modelo de integração latino-americana, superando o isolacionismo intercontinental de origem colonial. A integração passa a ter, igualmente, um conteúdo social mais acentuado.

-.Garante o poder de intervenção pública na economia, em oposição ao modelo de intervenção privada neoliberal.

Entre as características listadas por Vieira (2009), de destacar aquela pertinente ao registro de que o ponto de partida da teoria da novo constitucionalismo latino americano é o constitucionalismo de matriz europeia. Não se limita a isso, porém. Busca ultrapassá-lo a partir concretização da participação popular efetiva na elaboração e aprovação das constituições, não se reduzindo a mecanismos representativos de governo.

A Constituição de 1988, ainda que não compreendida como exemplo do Novo Constitucionalismo Latino-Americano, já que não porta uma concepção de ruptura (VICIANO PASTOR, 2011), aporta dispositivo normativo específico reconhecedor de direitos territoriais às comunidades quilombolas. 
Nesse sentido, dispõe o art. 68 do Ato das Disposições Constitucionais Transitórias que "Aos remanescentes das comunidades dos quilombos que estejam ocupando suas terras é reconhecida a propriedade definitiva, devendo o Estado emitir-lhes os títulos respectivo".

Apesar do reconhecimento constitucional de uma posição jurídica específica em favor dos quilombolas no tocante aos direitos territoriais, pouco se concretizou até o presente momento, ${ }^{7}$ o justifica a adoção do Novo Constitucionalismo Latino Americano para tentar garantir eficácia a esse dispositivo.

No ponto imediatamente abaixo, serão referidos os instrumentos jurídicos internacionais que podem ser lidos como pertinentes à proteção dos direitos territoriais das minorias étnicas, como o são as comunidades quilombolas.

\section{Referências normativas internacionais ${ }^{8}$}

No plano internacional, existem duas referências normativas que podem ser vinculadas à discussão sobre a regularização dos territórios quilombolas no Brasil. São duas convenções

\footnotetext{
${ }^{7}$ Nesse sentido, os dados são estarrecedores. Num universo de mais de três mil comunidades quilombolas existentes no país, distribuídas por quase todos os Estados da Federação (à exceção do Acre, Roraima e Distrito Federal), “[...] na atualidade existem [apenas] 120 títulos emitidos, regularizando 987.935,9873 hectares em benefício de 108 territórios, 189 comunidades e 11.918 famílias quilombolas, assim distribuídos: - De 1995 a 2002 foram expedidos 45 títulos regularizando $775.321,1193$ hectares em benefício de 42 territórios, 90 comunidades e 6.771 famílias quilombolas. Estes títulos foram expedidos por: FCP (13), FCP/INTERBA/CDABA (2), INCRA (6), ITERPA (16), ITERMA (4), ITESP (3) e SEHAF-RJ (1). Destes, 2 títulos do ITERPA foram expedidos a partir de parceria (técnica e/ou financeira) com o INCRA/MDA. - De 2003 a 2010 foram expedidos 75 títulos regularizando 212.614,8680 hectares em benefício de 66 territórios, 99 comunidades e 5.147 famílias quilombolas. Estes títulos foram expedidos por: INCRA (15), INTERPI/INCRA (5), SPU (2), ITERPA (30), ITERMA (19), ITESP (3) e IDATERRA-MS (1). Destes, 16 títulos do ITERPA e 14 do ITERMA foram expedidos a partir de parceria (técnica e/ou financeira) com o INCRA/MDA.". (Disponível em: $<$ http://ccr6.pgr.mpf.gov.br/institucional/grupos-de-trabalho/quilombos-1/documentos-1.>. Acesso em: 06 jan. 2012).

${ }^{8}$ Nesse campo, embora se tenha optado por discutir expressamente a Convenção Americana de Direitos Humanos e Convenção 169 da OIT, não podem ser esquecidos os pactos internacionais dos direitos civis e políticos e dos direitos econômicos, sociais e culturais, os quais, na percepção de Piovesan (2008, p. 293), constituem marco conclusivo do processo de juridização da Declaração Universal de 1948, vez que "[...] passaram a incorporar, com maior precisão e detalhamento, os direitos constantes da Declaração Universal, sob a forma de preceitos juridicamente obrigatórios e vinculantes [...]". Além disso, tem-se a Convenção para a Eliminação de Todas as Formas de Discriminação Racial, de 1965.
} 
90

internacionais: uma, a Convenção Americana de Direitos Humanos; outra, a Convenção n. ${ }^{\text {o }}$ 169, da Organização Internacional do Trabalho.

\subsection{A Convenção Americana de Direitos Humanos}

A Convenção Americana de Direitos Humanos, mais conhecida como "Pacto de San José de Costa Rica", foi assinada na Conferência Especializada Interamericana sobre Direitos Humanos, San José, Costa Rica, em 22 de novembro de 1969. A entrada em vigor dela ocorreu em 18 de julho de 1978, conforme o artigo 74.2 da Convenção. O instrumento original e ratificações encontram-se depositados na Secretaria-Geral da OEA. O seu registro na ONU se deu em 27 de agosto de 1979, sob o n. ${ }^{\circ}$ 17955. Atualmente conta com 34 países signatários, entre eles o Brasil. ${ }^{9}$

O Brasil a ratificou em 09 de julho de 1992, depositou o instrumento de ratificação em 25 de setembro de 1992 e reconheceu a competência da Corte Interamericana de Direitos Humanos em 10 de dezembro de 1998, ainda que sob reserva de reciprocidade e para fatos posteriores à declaração de reconhecimento. ${ }^{10}$

Graças a esta Convenção se criou a Corte Interamericana de Direitos Humanos como órgão ao qual cabe decidir se houve ou não violação dos direitos reconhecidos na Convenção nos casos que lhe forem submetidos.

A Convenção Americana dos Direitos Humanos prevê, no seu artigo 21, o direito à propriedade privada, assim:

1. Toda pessoa tem direito ao uso e gozo dos seus bens. A lei pode subordinar esse uso e gozo ao interesse social.

2. Nenhuma pessoa pode ser privada de seus bens, salvo mediante o pagamento de indenização justa, por motivo de utilidade pública ou de interesse social e nos casos e na forma estabelecidos pela lei.

3.

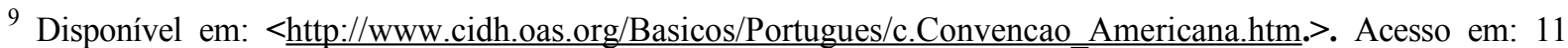
out. 2011.

${ }^{10}$ Disponível em: <http://www.cidh.oas.org/Basicos/Portugues/d.Convencao Americana Ratif..htm.>. Acesso em: 11 out. 2011.

R. Fac. Dir. UFG, V.36, n. 01, p. 85-108, jan./jun. 2012 ISSN $0101-7187$
} 
3. Tanto a usura como qualquer outra forma de exploração do homem pelo homem devem ser reprimidas pela lei. ${ }^{11}$

Apesar do artigo referido não definir os grupos beneficiários do direito à propriedade, a Corte Interamericana ${ }^{12}$ já tem reconhecido grupos negros (indivíduos, comunidades, povos etc) como titulares desse direito. Emblemáticos, nesse sentido, os casos Povo Suramaka vs. Suriname, ${ }^{13}$ de 28 de setembro de 2007, e o da Comunidad Moiwana vs. Suriname, julgado em 15 de junho de 2005.

Nesse último caso, no julgamento, a Corte declarou, relativamente ao direito de propriedade, que:

[...] El Estado violó el derecho a la propiedad consagrado en el artículo 21 de la Convención Americana, en relación con el artículo 1.1 de la misma, en perjuicio de los miembros de la comunidad Moiwana, en los términos del párrafo 135 de la presente [...]. 3. El Estado debe adoptar todas las medidas legislativas, administrativas y de cualquier otra índole, necesarias para asegurar a los miembros de la comunidad Moiwana su derecho de propiedad sobre los territorios tradicionales de los que fueron expulsados y asegurar, por lo tanto, el uso y goce de estos territorios. Estas medidas deberán incluir la creación de un mecanismo efectivo para delimitar, demarcar y asignar la titularidad de dichas tierras tradicionales, en los términos de los párrafos 209 a 211 de la presente Sentencia $[\ldots] .^{14}$

Esse julgamento pode ser tomado pelos governos latino-americanos, inclusive e necessariamente o brasileiro, como referência no trato dos povos indígenas e comunidades tradicionais, porque aponta para a necessidade de se adotar medidas efetivas para se delimitar, demarcar e atribuir titularidades dos territórios tradicionais a esses grupos, sob pena de responder no âmbito internacional.

Importante lembrar que o Brasil também responde no âmbito da Comissão InterAmericana dos Direitos Humanos por suposta violação de direitos das comunidades

\footnotetext{
${ }^{11}$ Disponível em: <http://www2.idh.org.br/casdh.htm.>. Acesso em: 22 nov. 2011.

12 Para maiores informações sobre a relação entre o sistema interamericano de direitos humanos e as comunidades negras rurais, com discussão sobre os limites e as possibilidades desse mecanismo judicial para a tutela dos direitos territoriais coletivos, ver Dulitzky (2010, p. 13-48).

${ }^{13}$ Rebelo (2009, p. 112-113), refletindo sobre a decisão proferida pela Corte no caso, anota que "[...] de acordo com as provas carreadas aos autos pelas partes, a Corte afirmou que o povo Saramaka forma uma comunidade tribal, organizada em clãs de linhagem materna - lös - e é um dos seis grupos que compõem a etnia Maroon, com aproximadamente 25 a 34 mil indivíduos, divididos em 63 comunidades situadas na região superior do rio Suriname e algumas outras comunidades situadas ao norte e a oeste dessa região anteriormente citada, sua forma de organização é baseada em seus próprios costumes e tradições e que a terra, além de fonte de subsistência, é parte de sua essência social, ancestral e espiritual [...]”. (grifou-se).

${ }^{14}$ Disponível em: $<$ http://www.corteidh.or.cr/docs/supervisiones/moiwana 21 1107 esp.pdf.>. Acesso em: 13 set. 2011.
}

R. Fac. Dir. UFG, V.36, n. 01, p. 85-108, jan. / jun. 2012 ISSN $0101-7187$ 
quilombolas de Alcântara, no Maranhão. Dois casos específicos foram levados à apreciação da Comissão: o caso dos quilombolas de Alcântara, no Maranhão (Caso n. $\left.{ }^{\circ} 12569\right)^{15}$ e o caso dos quilombolas da Ilha de Marambaia, no Rio de Janeiro (Petição n. ${ }^{\circ}$ 1450-09).

2.2 A Convenção sobre Povos Indígenas e Tribais

A Convenção sobre Povos Indígenas e Tribais foi adotada pela Conferência Geral da Organização Internacional do Trabalho em 27 de junho de 1989, em Genebra, na Suíça e entrou em vigor internacional em 5 de setembro de 1991. Apesar disso, apenas em 20 de junho de 2002, o Congresso Nacional brasileiro, pelo Decreto Legislativo $\mathrm{n}^{-}$143, aprovou o texto dela. No caso do Brasil, o depósito do instrumento de ratificação junto ao Diretor Executivo da OIT ocorreu em 25 de julho de 2002. A promulgação da Convenção ocorreu pelo Decreto Presidencial n ${ }^{\mathrm{o}} 5.051$, de 19 de abril de 2004. ${ }^{16}$

O que interessa diretamente para esta dissertação é saber quando entrou em vigor a Convenção 169 da OIT no Brasil, considerados os 4 (quatro) marcos temporais referidos e a necessidade de se definir sua aplicabilidade ou não no caso da ADI n. ${ }^{\circ}$ 3.239/DF.

Saber quando entrou em vigor depende de qual posição se adota no tocante à incorporação dos textos normativos internacionais ao direito interno (monista, dualista e dualista mitigada). ${ }^{17}$ Se se adota aquela clássica, cuja incorporação depende de ato legislativo, tal ocorreu em 25 de julho de 2003.

É que, nessa perspectiva, só após a aprovação pelo Congresso Nacional do texto dos tratados internacionais, pode o governo depositar o instrumento de ratificação. No caso da

\footnotetext{
${ }^{15}$ Disponível em: <http://www.cidh.org/annualrep/2006sp/Brasil555.01sp.htm.>. Acesso em: 24 nov. 2011.

${ }^{16}$ Disponível em: <http://www.institutoamp.com.br/oit169.htm.>. Acesso em: 15 set. 2011.

${ }^{17}$ Sobre essas três correntes, ver Rosa (2006, p. 97). Ainda que o escrito de Rosa seja, de fato, de 2004, quando defendeu sua tese de doutorado, sendo anterior à EC n. ${ }^{\circ} 45$, vai aqui referido por sua assunção clara sobre a questão, afirmando que os habitantes do território brasileiro não podem ficar na dependência da boa vontade do legislador quando o assunto é a incorporação dos direitos humanos positivados em instrumentos normativos internacionais ao ordenamento jurídico brasileiro. Segundo ele, a recepção deve ser automática, “[...] por força da interpretação conjunta do disposto nos parágrafos $1^{\circ}$ e $2^{\circ}$ face ao que consta do art. $5^{\circ} \mathrm{c} / \mathrm{c}$ art. $4^{\circ}$, II, todos da Constituição da República de 1988 [...]”'(ROSA, 2006, p. 97).
} 
Convenção 169, a aprovação ocorreu em 20 de junho de 2002, pelo Decreto Legislativo no 143, após o que, precisamente em 25 de julho de 2002, o governo fez o depósito da ratificação.

Como o artigo 38 da Convenção 169 dispõe que a Convenção entrará em vigor 12 meses após o registro de sua ratificação por parte do Diretor-Geral - relembre-se que ocorreu em 25 de julho de 2002 - , a passou a vigorar aqui no país em 25 de julho de 2003.

Mesmo que se adote a perspectiva tradicional quanto à matéria, quando da promulgado do Decreto n. ${ }^{\circ} 4.887$, em 20 de novembro de 2003, já vigia, portanto, no país, a Convenção 169 , como visto.

Importa também para o presente trabalho a regulamentação que a Convenção prevê sobre os direitos sobre a terra e da definição de autoidentificação e seus critérios objetivos e subjetivos, todos dela constantes.

No tocante à terra, assim está tratada a matéria, na Parte II da Convenção (art. 13 ao 17):

\section{PARTE II - TERRAS}

Artigo 13

1. Ao aplicarem as disposições desta parte da Convenção, os governos deverão respeitar a importância especial que para as culturas e valores espirituais dos povos interessados possui a sua relação com as terras ou territórios, ou com ambos, segundo os casos, que eles ocupam ou utilizam de alguma maneira e, particularmente, os aspectos coletivos dessa relação.

2. A utilização do termo "terras" nos Artigos 15 e 16 deverá incluir o conceito de territórios, o que abrange a totalidade do habitat das regiões que os povos interessados ocupam ou utilizam de alguma outra forma.

Artigo 14

1. Dever-se-á reconhecer aos povos interessados os direitos de propriedade e de posse sobre as terras que tradicionalmente ocupam. Além disso, nos casos apropriados, deverão ser adotadas medidas para salvaguardar o direito dos povos interessados de utilizar terras que não estejam exclusivamente ocupadas por eles, mas às quais, tradicionalmente, tenham tido acesso para suas atividades tradicionais e de subsistência. Nesse particular, deverá ser dada especial atenção à situação dos povos nômades e dos agricultores itinerantes.

2. Os governos deverão adotar as medidas que sejam necessárias para determinar as terras que os povos interessados ocupam tradicionalmente e garantir a proteção efetiva dos seus direitos de propriedade e posse.

3. Deverão ser instituídos procedimentos adequados no âmbito do sistema jurídico nacional para solucionar as reivindicações de terras formuladas pelos povos interessados.

$[\ldots]$

Artigo 17 
1. Deverão ser respeitadas as modalidades de transmissão dos direitos sobre a terra entre os membros dos povos interessados estabelecidas por esses povos.

2. Os povos interessados deverão ser consultados sempre que for considerada sua capacidade para alienarem suas terras ou transmitirem de outra forma os seus direitos sobre essas terras para fora de sua comunidade.

3. Dever-se-á impedir que pessoas alheias a esses povos possam se aproveitar dos costumes dos mesmos ou do desconhecimento das leis por parte dos seus membros para se arrogarem a propriedade, a posse ou o uso das terras a eles pertencentes. $[\ldots]{ }^{18}$

Dessa citação o que mais interessa diretamente para esta dissertação é o sentido construído para o termo terras (disposto no art. 13,2). Segundo esse preceito, deve-se incluir na extensão significativa do significante terras o conceito de territórios, "o que abrange a totalidade do habitat das regiões que os povos interessados ocupam ou utilizam de alguma outra forma".

Essa forma de conceber a configuração da territorialidade é muito importante, até porque foi utilizada no artigo $2^{\circ}, \S 2^{\circ}$, do Decreto . $^{\circ} 4.887$, dispositivo que foi questionado pelo DEM na ADI n. 3.239/DF, como se evidenciará mais à frente.

Quanto ao critério da auto-definição, assim estabelece a Convenção: “[...] 2. A consciência de sua identidade indígena ou tribal deverá ser considerada como critério fundamental para determinar os grupos aos que se aplicam as disposições da presente Convenção [...]." ${ }^{\prime 19}$

A aplicabilidade dos dispositivos desta Convenção 169 às comunidades quilombolas é questionada na ação direta de inconstitucionalidade 3.239-9/DF. A Associação Brasileira de Celulose e Papel (BRACELPA), por exemplo, na manifestação constante dos autos do processo da ação referida, defende que "[...] se mostra clara a inaplicabilidade dessa Convenção aos remanescentes das comunidades dos quilombos, porque não se trata de povos tribais nem de povos indígenas [...]" ${ }^{20}$

Dada a pertinência da temática referida pelo Boletim n. ${ }^{\circ}$ 07, intitulado "A OIT e os povos indígenas e tribais", focado que está na matéria da "discriminação", com o tema dessa dissertação, importante breve referência ao seu teor.

\footnotetext{
${ }^{18}$ Disponível em:< http://www.institutoamp.com.br/oit169.htm.. . Acesso em: 15 set. 2011.

${ }^{19}$ Disponível em: $<\underline{\text { http://www.institutoamp.com.br/oit169.htm'> }}$. Acesso em: 15 set. 2011.

${ }^{20}$ Disponível

em:

$<$ http://redir.stf.jus.br/estfvisualizadorpub/jsp/consultarprocessoeletronico/ConsultarProcessoEletronico.jsf? seqobjetoincidente $=2227157>$. Acesso em: 25 jan. 2012.
} 
Segundo o Boletim (2007),

\begin{abstract}
La situación en América Latina difiere de la de otras regiones del mundo. Mientras que, lamentablemente, el Convenio núm. 169 no cuenta con ratificaciones en continentes como Asia y África, este tratado internacional cuenta ya con un gran número de ratificaciones entre los Estados latinoamericanos (Argentina, Bolivia, Brasil, Colombia, Costa Rica, Ecuador, Guatemala, Honduras, México, Paraguay, Perú y Venezuela lo han ratificado). También pueden encontrarse importantes pasos en el proceso de implementación del Convenio. Prácticamente todos los Estados partes han efectuado reformas legislativas que de una u otra forma incorporan disposiciones relativas a pueblos indígenas. También se han elaborado y llevado a cabo en varios de estos países programas y políticas públicas para la mejora de la situación de los pueblos indígenas. Sin embargo, la región aún enfrenta grandes retos en la implementación del Convenio. ${ }^{21}$
\end{abstract}

Pelo teor da citação supra, de destacar a ratificação da Convenção por alguns países latino-americanos, inclusive o Brasil, e a adoção de providências internas a cada país visando implementá-la.

No Brasil, um exemplo de providência interna no sentido de aplicar as disposições da Convenção, é o Decreto n. ${ }^{\circ} 4.887$, de 20 de novembro de 2003, cujo artigo $2^{\circ}$, $1^{\circ}$, reconhece que "[...] Para os fins deste Decreto, a caracterização dos remanescentes das comunidades dos quilombos será atestada mediante autodefinição da própria comunidade[...]". O critério da autodefinição adotado para a caracterização das comunidades quilombolas corresponde ao critério da consciência da identidade indígena ou tribal para identificação dos grupos indígenas ou tribais, a que se refere a convenção. ${ }^{22}$

No tocante à implantação da Convenção no país, um dos obstáculos é a própria Ação Direta de Inconstitucionalidade n. ${ }^{\circ} 3.239 / \mathrm{DF}$, que imputa inconstitucionalidade ao Decreto . $^{\mathrm{o}}$ 4.887/2003, sendo um dos argumentos invocados a previsão nele do critério da autodefinição para identificação dos quilombolas. Na visão do partido político que propôs a ação, o texto regulamentar, ao acolher o critério da autoidentificação para identificar os quilombolas,

[...] resume a rara característica de remanescente de comunidade quilombola numa mera declaração de vontade do interessado [...]. À toda evidência, submeter a qualificação constitucional a uma declaração do próprio interessado nas terras importa radical subversão da lógica constitucional. Segundo a letra da Constituição,

\footnotetext{
${ }^{21}$ Disponível em: <http://util.socioambiental.org/inst/esp/consulta_previa/sites/util.socioambiental.org.inst.esp. consulta_previa/files/bolet\%C3\%ADn_c169oit_2007.pdf .>. Acesso em: 14 set. 2011.

22“"Artigo $1^{\circ}[\ldots] 2$. A consciência de sua identidade indígena ou tribal deverá ser considerada como critério fundamental para determinar os grupos aos que se aplicam as disposições da presente Convenção.”. Disponível em: <http://www.institutoamp.com.br/oit169.htm. $>$. Acesso em: 14 nov. 2011.
} 
seria necessário e indispensável comprovar a remanescência - e não a descendência - das comunidades dos quilombos para que fossem emitidos os títulos $[\ldots] .{ }^{23}$

Ocorre que, como demonstrando, uma vez estando a Convenção 169 da OIT em vigor no Brasil desde antes da promulgação do Decreto . $^{\circ}$ 4.887/03, com a explícita adoção do critério da auto-identificação, resta sem fundamentação jurídica adequada a argumentação tecida pelo DEM na petição inicial da ADI n. ${ }^{\circ}$ 3.239/DF.

\section{A regulamentação jurídica da titulação no ordenamento jurídico interno}

Limitam-se as referências ao elaborado no âmbito federal. Não serão discutidos os instrumentos jurídicos adotados pelos estados membros para a regularização. Vale mencionar que também foram apresentados vários projetos de lei e propostas de emendas constitucionais, tentando regulamentar a matéria, porém, sem sucesso em termos de promulgação. ${ }^{24}$

\subsection{As portarias}

A primeira referência normativa geral e abstrata pertinente à questão quilombola no Brasil, no âmbito federal, depois da referência na Constituição Federal de 1988 e em algumas

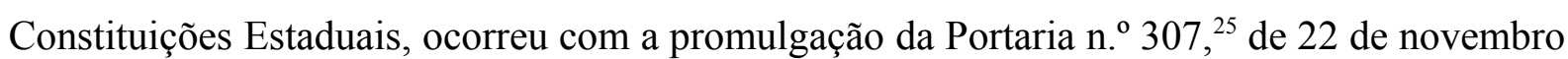
de 1995, pelo Presidente do Instituto Nacional de Colonização e Reforma Agrária (INCRA).

\footnotetext{
${ }^{23}$ Disponível em: $\quad$ http://redir.stf.jus.br/estfvisualizadorpub/jsp/consultarprocessoeletronico/Consultar ProcessoEletronico.jsf? seqobjetoincidente $=2227157$. . $^{\text {. Acesso em: } 15 \text { nov. } 2011 .}$

${ }^{24}$ Sobre as várias tentativas de regulamentação do tema, ver Trecani (2006), o qual levanta as várias iniciativas desenvolvidas nesse sentido, a saber: o PL n 627/95, de Alcides Modesto, o PL n ${ }^{\circ}$ 129/95, de Benedita da Silva, o PL no 3.207/97, do Deputado Luiz Alberto (PT-BA), PL 3.081/00, do deputado Paulo Mourão, o PL n. 5.447/01, do Deputado Jairo Carneiro (PFL-BA), o PL n 6.912 - Estatuto da Igualdade Racial, do Deputado Paulo Paim (PT/RS), que reuniu os PLs $\mathrm{n}^{\circ} 3.198$, de 7 de junho de 2000, $\mathrm{n}^{\circ} 3.435$, de 8 de agosto de 2000 e $\mathrm{n}^{\circ}$ 6.214/02, esse último de autoria do deputado Pompeo de Mattos; o PL n ${ }^{\circ}$ 213/2003, de Paulo Paim, falando em desapropriação para fins étnicos; e a PEC n 38/97, de autoria do Senador Abdias Nascimento, arquivada em 29 de janeiro de 1999; e a PEC n 6/99, proposta pelo senador Lúcio Alcântara PSDB/CE.

${ }^{25}$ Disponível em: <http://www.cpisp.org.br/htm/leis/fed4.htm.>. Acesso em: 06 nov. 2011. 
Nela consta a primeira proposta quanto à forma de titulação dos territórios quilombolas, que deveria ser mediante a concessão de título de reconhecimento às comunidades quilombolas, com cláusula pro indiviso, expedido pelo INCRA (arts. I e II).

Segundo Chasin (2009), “[...] seis títulos foram outorgados pelo Incra sob a égide da Portaria 307/1995 [...]”, sendo que “[...] o primeiro título foi concedido em 20 de novembro de 1995, beneficiando a comunidade Boa Vista, no município de Oriximiná (PA) [...]”.

Antes dessa Portaria, foram propostas 3 (três) ações judiciais. Duas na Bahia e uma em São Paulo. Naquele Estado, as ações foram propostas pelo Ministério Público Federal, em benefício da comunidade Rio das Rãs. Nesse Estado, próprios membros da Comunidade de Ivaporunduva ajuizaram ação declaratória (n. $\left.{ }^{\circ} 94.0020556-2\right){ }^{26}$

A segunda referência foi a Portaria n. ${ }^{\circ} 447,{ }^{27}$ de 02 de dezembro de 1999, pela qual o ministro de Estado da Cultura delegou competência à titular da Presidência da Fundação Cultural Palmares. Referida Portaria foi editada com base na Medida Provisória n. ${ }^{0} 1911,{ }^{28}$ a qual, ao passar pela $11^{\mathrm{a}}$ (décima primeira) alteração, de 26 de outubro de 1999, atribuiu ao Ministério da Cultura a competência para cumprimento do disposto no art. 68 do Ato das Disposições Constitucionais Transitórias. Nela inexiste previsão de forma jurídica para cumprimento do art. 68 do ADCT. Apenas há referência à delegação de competência à Fundação Cultural Palmares. $^{29}$

Comparando-se as duas portarias, tem-se que, da passagem da primeira para a segunda, houve mudança quanto ao órgão responsável pela titulação. Inicialmente era o INCRA; depois passou a ser a FCP. Ademais, enquanto na primeira havia previsão quanto à forma de titular, na segunda isso não foi previsto.

\footnotetext{
${ }^{26}$ Ainda que proposta ação declaratória combinada com ordinária no ano de 1994, o processo só recebeu sentença em 20 de novembro de 2002, ou seja, quase oito anos depois, a qual reconheceu a qualidade de remanescentes de quilombos aos associados da Associação que propôs a ação e determinou à União que titulasse a área. $\mathrm{O}$ inteiro teor da sentença está disponível em:

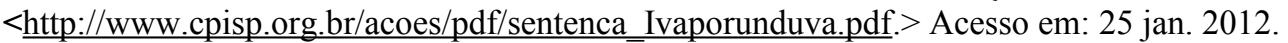

27 Disponível em: <http://www.cultura.gov.br/site/wp-content/uploads/2007/11/portaria-447-de-1999.pdf>. Acesso em: 06 nov. 2011.

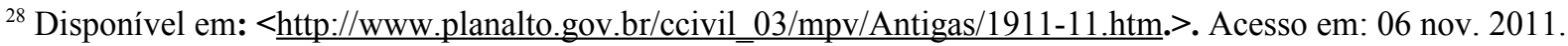
${ }^{29}$ Segundo a Portaria, o Ministro do Estado da Cultura resolveu: "Art. $1^{\circ}$ Delegar competência à titular da Presidência da Fundação Cultural Palmares para praticar e assinar os atos necessários ao efetivo cumprimento do disposto no artigo 68 do Ato das Disposições Constitucionais Transitórias, atendidas as prescrições legais pertinentes.” Disponível em: $<$ http://www.cultura.gov.br/site/wp-content/uploads/2007/11/portaria-447-de1999.pdf.>. Acesso em: 06 nov. 2011.
} 
De destacar que essa Medida Provisória e respectiva Portaria eram insuficientes para embasar a eficácia do artigo 68 da Constituição Federal. Tanto que algumas associações de comunidades quilombolas impetraram perante o Supremo Tribunal Federal, no ano de 2000, um mandado de injunção, sustentando a mora do executivo em regulamentar a matéria. ${ }^{30}$

\subsection{Os Decretos}

O referencial normativo posterior à citada Portaria foi o Decreto n. ${ }^{\circ} 3.912,{ }^{31}$ de 10 de setembro de 2001, hoje revogado por suas evidentes inconsistências jurídicas, que serão referidas abaixo.

Ainda que revogado, é importante refletir sobre algumas questões que surgiram com sua promulgação. A primeira delas era a condição exigida para se reconhecer a propriedade das terras em favor das comunidades quilombolas. Era necessário que a ocupação das terras por quilombos datasse de 1888 e estivessem ocupadas por remanescentes de comunidades de quilombos em 1988 (art. 1º , e II).

Além de se exigir um lapso temporal literalmente secular, vinha a exigência de que, inicialmente, lá em 1888 (no século dezenove), a ocupação da terra fosse por quilombos e, em 1988, por remanescentes.

Evidente que não seria nada fácil, para não dizer impossível, provar ocupação por 100 (cem) anos. Que testemunhas viveriam tanto tempo e com memória tão lúcida para dar conta que, entre 1888 e 1988, as terras estiveram sob ocupação, primeiro por quilombo, depois por remanescentes?

\footnotetext{
BRASIL. Supremo Tribunal Federal. Mandado de Injunção n. ${ }^{\circ}$ 630. Relator: Joaquim Barbosa. Julgamento: 05 dez. 2005. A impetração é datada de 21 de junho de 2000. Na fundamentação houve indicação de omissão do Presidente da República, em relação a providências necessárias à concretização do direito previsto no art. 68 do Ato das Disposições Constitucionais Transitórias da Constituição de 1988. Dado que, durante o curso do processo, foram expedidos os decretos (primeiro o de . $^{\circ} 3.142$, de 10 de setembro de 2001; depois o de . $^{\circ}$ 4.887, de 20 de novembro de 2003), o pedido, no ponto relativo à regulação administrativa da matéria, foi julgado prejudicado. Disponível em: $<$ http://www.stf.jus.br/portal/jurisprudencia/listarJurisprudencia. asp?s1= \%28MI\%24\%2ESCLA\%2E+E+630\%2ENUME\%2E\%29\&base=baseMonocraticas.>. Acesso em: 11 nov. 2011. ${ }^{31}$ Disponível em: $<$ http://www81.dataprev.gov.br/sislex/paginas/23/2001/3912.htm $>$. Acesso em: 10 nov. 2011. 
Analisando essa questão sob a ótica do princípio da proporcionalidade e da razoabilidade, Beckhausen (2007, p. 25) afirma que:

[...] tal requisito não é razoável, violando totalmente, os princípios constitucionais vigentes. Além disso, a coleta da prova vai se tornar extremamente difícil, para não dizer impossível. Produzir um conjunto probatório utilizando material com mais de um século de existência é tarefa hercúlea. Os experts teriam imensas dificuldades para conseguir demonstrar uma ocupação ocorrida nesta época. Não é, portanto, razoável estabelecer esse período [...].

Outra questão foi a relativa à competência para a instauração, movimentação e conclusão do processo administrativo de identificação dos remanescentes das comunidades dos quilombos, bem como de reconhecimento, delimitação, demarcação, titulação e registro imobiliário das terras por eles ocupadas.

Manteve-se a atribuição com a Fundação Cultural Palmares, o que também foi objeto de crítica. Reis (2011), mesmo reconhecendo o órgão como importante e representativo de um expressivo avanço no campo institucional, não o vê como adequado para a tarefa de regularização, por carecer de “[...] estrutura técnica, disponibilidade orçamentária e capacidade jurídica $[\ldots] "$.

Uma terceira controvérsia referia-se ao silêncio do decreto quanto à questão fática da existência de comunidades quilombolas sobre áreas tituladas, sobre propriedades privadas. $\mathrm{Na}$ perspectiva de Duprat (2007, p. 39), esse silêncio fazia o decreto padecer de vício de ilegalidade “[...] porque não enfrenta, sequer remotamente, a questão da incidência desses remanescentes de comunidades de quilombos em áreas já tituladas, sob domínio privado, ao não disciplinar os aspectos que necessariamente o tangenciam, como a necessidade, forma e procedimento da desapropriação, nulidade ou não de títulos privados [...]”.

\subsection{O Decreto n. ${ }^{\circ} 4.887 / 2003$}


100

Resultado do trabalho de um grupo de interministerial constituído por decreto do Presidente da República, ${ }^{32}$ coordenado pela SEPPIR e pela Casa Civil, com o fim de definir ações e políticas públicas em benefício das comunidades quilombolas, o Decreto n. $^{\circ} 4.887$, de 20 de novembro de 2003, foi promulgado pelo Presidente da República como providência executiva para efetivação do direito de propriedade às comunidades quilombolas, referindo uma séria de questões, que se passa a discorrer.

O objetivo principal desse decreto é fixar o procedimento viabilizador da regularização fundiária em benefício das comunidades quilombolas.

O uso da expressão regularização fundiária na linguagem jurídica traduz basicamente duas significações, podendo traduzir, assim, tanto o nome de um instituto do Direito Agrário quanto o processo de titulação dos territórios das comunidades quilombolas.

No primeiro sentido de regularização fundiária, Stefanini (1978, p. 159) conceitua a regularização de posse como sendo "[...] um modo derivado, oneroso e preferencial de aquisição de terras públicas, mediante procedimento típico do órgão executivo, em benefício daqueles que, achando-se na posse destas terras nas formas e sujeições da lei, fazem por provocar a liberalidade do poder público de alienar-lhes as terras apossadas, independentemente de concorrência pública [...]".

No segundo sentido, falar no verbo regularizar significa garantir titulação aos respectivos beneficiários, no caso, as comunidades quilombolas, na crença de que isso proporcionaria segurança à posse e escrituração à propriedade e, consequentemente, tranquilidade e paz aos titulares do direito.

A regularização, no segundo sentido, é vislumbrada como fazendo “[...] parte de uma política fundiária, que envolve outros instrumentos importantes como a legitimação de posse, a discriminação e a arrecadação [...]” (FAIDHERB, 2009, p. 17) de terras.

Discorrendo sobre a regularização fundiária levada a efeito pelo IDAGO (Instituto de Desenvolvimento Agrário do Estado de Goiás), na área Kalunga situada no município de

\footnotetext{
$32 \mathrm{O}$ decreto referido não recebeu numeração. Ele foi editado em 13 de maio de 2003, tendo por objetivo a revisão das "[...] disposições contidas no Decreto n. 3.912, de 10 de setembro de 2001, e propor nova regulamentação ao reconhecimento, delimitação, demarcação, titulação, registro imobiliário das terras remanescentes de quilombos [...]". Disponível em: <http://www.cpisp.org.br/htm/leis/page.aspx?LeiID=133>. Acesso em: 20 jan. 2012.
} 
Monte Alegre de Goiás, na década de 1980, que beneficiou 220 famílias quilombolas, Soares (1993, p. 68) anota que, com a ela, “[...] a posse agrária passou a ser também [...] propriedade imobiliária $[\ldots]$ ”.

Interessa a este artigo este sentido de regularização fundiária enquanto processo de identificação, reconhecimento, delimitação, demarcação e titulação de territórios quilombolas, porque remete diretamente ao reconhecimento aos quilombolas dos direitos de propriedade e de posse sobre os territórios que ocupam.

Esse processo, atualmente regulamentado pelo Decreto $\mathrm{n}^{\circ} 4.887$, de 20 de novembro de 2003, pela Instrução Normativa $n^{0}$ 49, de 29 de setembro de 2008, e pela Instrução Normativa n. ${ }^{\circ}$ 57, de 20 de outubro de 2009, conglomera diversas etapas, a saber: identificação, reconhecimento, delimitação, demarcação e titulação.

Concluindo esse tópico, de destacar que o decreto apresenta, desde a perspectiva jurídica adotada na elaboração deste artigo, aspectos positivos e negativos. Entre os primeiros, está a atribuição da competência para regularizar os territórios quilombolas ao INCRA, órgão fundiário por excelência, sem prejuízo que a mesma atribuição seja desenvolvida pelos Estados ou Municípios, a adoção do critério da auto-atribuição, em sintonia com a Convenção 169 da OIT, para identificar os quilombolas e a definição de território quilombola e a forma de caracterização do mesmo.

Em termos de definição e caracterização do território, o artigo $2^{\circ}, \S \S 2^{\circ}$ e $3^{\circ}$, dispõe que:

$\S 2^{\circ}$ São terras ocupadas por remanescentes das comunidades dos quilombos as utilizadas para a garantia de sua reprodução física, social, econômica e cultural. $\S 3^{\circ}$ Para a medição e demarcação das terras, serão levados em consideração critérios de territorialidade indicados pelos remanescentes das comunidades dos quilombos, sendo facultado à comunidade interessada apresentar as peças técnicas para a instrução procedimental. ${ }^{33}$

Ademais, o Decreto não repete os vícios do anterior, como aquelas exigências desproporcionais de se apresentar prova documental da descendência de escravos fugidos e de posse imemorial, de 1 (um) século.

\footnotetext{
${ }^{33}$ Disponível em: < http://www.cpisp.org.br/htm/leis/page.aspx?LeiID=184.>. Acesso em: 18 nov. 2011. 
Entre os pontos negativos estão a exigência de certificação da comunidade como remanescente de quilombo pela Fundação Cultural Palmares, o que é questionável em face do critério da auto-identificação, o uso da expressão remanescentes das comunidades de quilombos, a qual não coloca em primeiro plano a coletividade, mas o passado, e a quantidade de fases do processo administrativo de titulação.

O ponto mais polêmico do Decreto é a possibilidade de desapropriação de áreas particulares para titulação dos territórios quilombolas, vista com bons olhos pelos INCRA.

De qualquer forma, atualmente, não se constata argumentos sólidos a afastar a legitimidade da política pública de regularização de territórios quilombolas. Ocorre, porém, que existem "[...] obstáculos político-institucionais para titular e garantir os direitos étnicos à terra [...]" (ALMEIDA, 2006), destacando-se a própria ação direta de inconstitucionalidade n. 3.239/DF em tramitação no Supremo Tribunal, ${ }^{34}$

\section{O Programa Brasil Quilombola}

Em contraposição a esse obstáculo concreto há o Programa Brasil Quilombola. Esse Programa traduz política pública, vale dizer “[...] programa de ação [...]”, que “[...] não é uma norma nem um ato [...]”, muito embora a política “[...] acaba por englobá-los como seus componentes [...]" (COMPARATO, 1998, p. 44) ${ }^{35}$. Isso justifica, em parte, o feitio social do direito de propriedade dos territórios.

\footnotetext{
${ }^{34}$ Um outro obstáculo que foi oposto ao Decreto n. ${ }^{\circ} 4.887 / 03$ foi a proposta de Decreto Legislativo, em 17 de maio de 2007. O deputado federal Valdir Colato, a partir da situação da Invernada dos Negros/SC, propôs a sustação da aplicação do decreto executivo referido, alegando, em suma, exorbitância do poder regulamentar pelo chefe do executivo, com consequente anulação dos atos administrativos expedidos com base neste. A proposta restou rejeitado.

${ }^{35}$ Como será visto adiante, o Decreto n. ${ }^{\circ} 4.887$, de 20 de novembro de 2003, insere-se no contexto dessa política, configurando texto normativo que a instrumentaliza para aplicação nas relações respectivas. Nesse mesmo contexto, foram editados os decretos n. 4883 e 4885, os quais, porém, não são objeto de ação de inconstitucionalidade.
} 
Essa política está estruturada sobre quatro eixos, a saber: acesso à terra, infraestrutura e qualidade de vida, desenvolvimento local e inclusão produtiva e direitos de cidadania ${ }^{36}$.

Apesar do esforço que se há de reconhecer nas ações do Poder Executivo Federal em prol da estruturação de uma política de tal envergadura, não se pode deixar de apontar algumas falhas, no pertinente aos eixos anunciados. Por óbvio, as falhas constatadas o são desde a perspectiva teórica adotada neste artigo, que é aquela do novo constitucionalismo latino-americano.

A primeira falha está na não diferenciação entre terra, território e territorialidades específicas, tão cara a alguns autores da antropologia e do próprio direito. ${ }^{37}$ [Adota-se neste artigo a perspectiva de que os termos terra e território não têm a mesma extensão significativa. O segundo tem sentido mais amplo do que o primeiro, pelo que vai adotado. Souza Filho (2001, p. 15) anota que "[...] É claro que há uma não muito sutil diferença entre chamar de terra e território. Terra é o nome jurídico que se dá à propriedade individual, seja pública ou privada; território é o nome jurídico que se dá a um espaço jurisdicional. Assim, o território é um espaço coletivo que pertence a um povo [...]". No campo antropológico também não há sinonímia entre esses conceitos. Para uma discussão pormenorizada disso, ver Almeida (2008, p. 05) e Arruti (2006, p. 119). No âmbito da juridicidade, há o Decreto n. ${ }^{\circ} 6.040$, de 7 de fevereiro de 2007 - o qual institui a Política Nacional de Desenvolvimento Sustentável dos Povos e Comunidades Tradicionais -, onde foi delineado que os territórios tradicionais referem-se aos "[...] espaços necessários a reprodução cultural, social e econômica dos povos e comunidades tradicionais, sejam eles utilizados de forma permanente ou temporária [...]”.]. Falar em "acesso à terra" configura reducionismo, vez que omitidas outras concepções de territorialidades construídas no âmbito de atuação de cada grupo social, em sua singularidade.

\footnotetext{
${ }^{36}$ Ver, sobre esses eixos, o documento "Programa Brasil Quilombolas - Relatório de Gestão 2009". Disponível em: <http://www.seppir.gov.br/.arquivos/relatorio gestao pbq2009.>. Acesso em: $25 \mathrm{dez}$. 2011. Segundo o disposto nesse documento: "O Programa Brasil Quilombola (PBQ) reúne 23 ministérios do Governo Federal, além de empresas públicas e sociedades de economia mista, que integram um expressivo conjunto de ações que atendem às comunidades remanescentes de quilombos no país." (SEPPIR, 2009, p. 4).

${ }^{37}$ Adota-se neste artigo a perspectiva de que os termos terra e território não têm a mesma extensão significativa. O segundo tem sentido mais amplo do que o primeiro, pelo que vai adotado. Souza Filho $(2001$, p. 15) anota que “[...] É claro que há uma não muito sutil diferença entre chamar de terra e território. Terra é o nome jurídico que se dá à propriedade individual, seja pública ou privada; território é o nome jurídico que se dá a um espaço jurisdicional. Assim, o território é um espaço coletivo que pertence a um povo [...]". No campo antropológico também não há sinonímia entre esses conceitos. Para uma discussão pormenorizada disso, ver Almeida (2008, p. 05) e Arruti (2006, p. 119). No âmbito da juridicidade, há o Decreto n. ${ }^{\circ} 6.040$, de 7 de fevereiro de 2007 - o qual institui a Política Nacional de Desenvolvimento Sustentável dos Povos e Comunidades Tradicionais -, onde foi delineado que os territórios tradicionais referem-se aos "[...] espaços necessários a reprodução cultural, social e econômica dos povos e comunidades tradicionais, sejam eles utilizados de forma permanente ou temporária $[\ldots] "$.
}

R. Fac. Dir. UFG, V.36, n. 01, p. 85-108, jan./jun. 2012 ISSN $0101-7187$ 
Além disso, na fundamentação deste eixo de "acesso à terra", não foi mencionado o Estatuto da Terra. Falha grave, vez que a Lei $4.504,{ }^{38}$ de 30 de novembro de 1964 , regulamenta "[...] as condições e as possibilidades de acesso à terra [...]” (MEDEIROS, 1996, p. 11).

A segunda falha reside na dissociação do acesso à terra como um direito de cidadania. Essa conclusão parece evidente, na medida em que são tratadas como eixos diferentes, quando deveriam ser vistos em perspectiva integrada (HERRERA FLORES, 2009), valorizando o acesso à terra - ou melhor, o acesso ao território - como direito de cidadania. Essa crítica não é simples preciosismo linguístico, apenas destaca a importância de se vincular questões de apropriação territorial à linguagem dos direitos, fundamental para uma discussão minimamente séria, até para se exigir judicialmente o cumprimento, a efetividade dos direitos coletivos e individuais territoriais, dos quais, ao menos formalmente, são titulares os quilombolas.

Nota-se terceira falha na adesão incondicional ao ideário do desenvolvimento sustentável, ${ }^{39}$ sem se preocupar com a concepção que cada grupo quilombola, na sua singularidade, tem sobre desenvolvimento, nem referir outras concepções de desenvolvimento existentes, como a de Sen (2010).

Apesar disso, essa política pode ser tida como a primeira a traduzir preocupação governamental federal com a questão quilombola, já que inexistentes programas de ação dessa feição em governos passados, inclusive durante todo o período republicano, o que impossibilita que se ventile a existência de outras fases de política semelhante.

Isso é digno de nota, porque parece revelar uma contradição, não aceitável à primeira vista, na medida em que, pelo menos até 1888 , os escravos estavam incluídos no circuito mercadológico, vistos que eram como mercadorias livremente trocáveis.

Por fim, parece que essa política pública contribui para a materialização das mediações institucionais de que fala Ricoeur (2008), em prol, numa leitura contextualizada,

\footnotetext{
38 “Art. $2^{\circ}$. É assegurada a todos a oportunidade de acesso à propriedade da terra, condicionada pela sua função social, na forma prevista nesta Lei”.

${ }^{39}$ Para uma análise da relação entre o desenvolvimento sustentável e a agricultura integrada, a partir inclusive do caso brasileiro do café sombreado na serra do Baturité, ver Tarrega (2010, p. 79-106).
} 
do reconhecimento da necessidade de se garantir efetividade aos direitos subjetivos dos membros e das comunidades quilombolas.

O problema é que essa rede institucional está excessivamente centralizada em BrasíliaDF, o que é uma contradição evidente, já que a capital federal não contempla sequer uma comunidade quilombola.

\section{CONCLUSÃO}

$\mathrm{Na}$ complexa e intrigada questão da regularização dos territórios quilombolas, destacam-se os marcos normativos como pontos de partida para uma discussão hermenêutica. O constitucionalismo de feitio apenas europeu não se mostra suficiente como base teórica para a concreção dos direitos territoriais dos quilombolas, vez que não atenta à diversidade social, que exige novo olhar, mais flexível e que reconheça a diferença.

Daí porque o Novo Constitucionalismo Latino Americano desponta como perspectiva teórica para qualquer discussão que envolva direitos territoriais quilombolas. É que ele se ocupa de problemas das minorias étnicas voluntariamente não lembradas no discurso jurídico tradicional, numa perspectiva sensível ao outro diferente.

No que toca especificamente aos direitos territoriais das comunidades quilombolas, essa nova perspectiva teórica oferece um visão de combate à marginalização social das minorias étnicas, bem assim uma orientação ao reconhecimento da diferença, expressa, por exemplo, no reconhecimento de formas plurais de apropriação do território por diferentes comunidades quilombolas.

No âmbito da existência formal, tanto a Convenção Americana de Direitos Humanos - associada ao funcionamento da Comissão Interamericana de Direitos Humanos e da Corte Interamericana dos Direitos Humanos - quanto a Convenção sobre os Povos Indígenas e Tribais, despontam como referenciais normativos internacionais que podem e devem amparar o debate sobre a concreção de direitos territoriais das comunidades quilombolas brasileiras. Elas aparecem como vetores de uma hermenêutica construtiva, aberta para novos horizontes 
jurídicos de proteção dos seres humanos e das comunidades quilombolas, orientada inclusive no sistema regional latino-americano.

No âmbito interno, além do art. 68 do ADCT, que garante formalmente aos quilombolas direitos territoriais, há o Decreto $n^{\circ}{ }^{o} 4.887 / 03$, que aufere legitimidade nos instrumentos normativos internacionais citados bem assim no próprio texto constitucional, parâmetro que o valida como instrumento de concreção constitucional, pelo que deve ser mantido no ordenamento jurídico brasileiro como base da política pública de regularização dos territórios quilombolas.

A esperança é que os quilombolas sintam e usufruam dos territórios que por direto lhes pertencem, num horizonte de fortalecimento do sentimento de respeito às diferenças.

\section{REFERÊNCIAS BIBLIOGRÁFICAS}

ALMEIDA, Alfredo Wagner Berno de. Terra e territórios: a dimensão étnica e ambiental dos conflitos agrários. In: Conflitos no Campo Brasil 2006 (Coord. Afonso, José Batista Gonçalves; Canuto, Antônio; Luz, Cássia Regina da Silva; Santos, Maria Madalena). Goiânia: CPT, 2006.

Terra de quilombo, terras indígenas, "babaçuais livres", "castanhais do povo", faixinais e fundos de pasto: terras tradicionalmente ocupadas. 2. ed. Manaus: PGSCA-UFAM, 2008

ARRUTI, José Maurício. Mocambo: antropologia e história do processo de formação quilombola. Bauru, SP: Edusc, 2006.

BECKHAUSEN, Marcelo. A inconstitucionalidade do Decreto 3912, de 10 de setembro de 2001. In: DUPRAT, Débora (Org.). Pareceres Jurídicos: direito dos povos e comunidades tradicionais. Manaus. UEA, 2007.

BRASIL. Constituição da República Federativa do Brasil (1988). Disponível em: $<$ http://www.planalto.gov.br/ccivil 03/constituicao/constitui\%C3\%A7ao.htm.>. Acesso em: 23 jan. 2012.

. Decreto n. ${ }^{\circ} 4.887$, de 20 de novembro de 2003. Regulamenta o procedimento para identificação, reconhecimento, delimitação, demarcação e titulação das terras ocupadas por remanescentes das comunidades dos quilombos de que trata o art. 68 do Ato das Disposições Constitucionais Transitórias. Disponível em: $<$ http://www.planalto.gov.br/ccivil 03/decreto/2003/d4887.htm. >. Acesso em: 25 jan. 2012.

. Decreto n. $^{\circ} 3.912$, de 10 de setembro de 2001. Regulamenta as disposições relativas ao processo administrativo para identificação dos remanescentes das comunidades dos quilombos e para o reconhecimento, a delimitação, a demarcação, a titulação e o registro imobiliário das terras por eles ocupadas. Disponível em:< http://www81.dataprev.gov.br/sislex/paginas/23/2001/3912.htm>. Acesso em: 10 nov. 2011.

. Decreto sem número, de 13 de maio de 2003. Institui Grupo de Trabalho com a finalidade de rever as disposições contidas no Decreto $n^{\circ} 3.912$, de 10 de setembro de 2001, e propor nova regulamentação ao reconhecimento, delimitação, demarcação, titulação, registro imobiliário das terras remanescentes de quilombos e dá outras providências. Disponível em: <http://www.cpisp.org.br/htm/leis/page.aspx?LeiID=133>. Acesso em: 20 jan. 2012. 
Fundação Cultural Palmares (2012). Disponível em: <http://www.palmares.gov.br/?page id=88>. Acesso em: 15 jun. 2012.

Instituto Nacional de Colonização e Reforma Agrária (INCRA). Balanço da Gestão da PFE/INCRA de 2003/2010 \& Perspectivas: um compromisso com a Reforma Agrária. Brasília: INCRA, 2011.

- Instrução Normativa n. 49 do INCRA. Regulamenta o procedimento para identificação, reconhecimento, delimitação, demarcação, desintrusão, titulação e registro das terras ocupadas por remanescentes das comunidades dos quilombos de que tratam o Art. 68 do Ato das Disposições Constitucionais Transitórias da Constituição Federal de 1988 e o Decreto $n .^{\circ} 4.887$, de 20 de novembro de 2003.

- Instrução Normativa n. 57 do INCRA. Regulamenta o procedimento para identificação, reconhecimento, delimitação, demarcação, desintrusão, titulação e registro das terras ocupadas por remanescentes das comunidades dos quilombos de que tratam o Art. 68 do Ato das Disposições Constitucionais Transitórias da Constituição Federal de 1988 e o Decreto $n .^{\circ} 4.887$, de 20 de novembro de 2003.

. Justiça Federal. Ação de rito ordinário sob n 94.0020556-2. Juíza Sentenciante: Maria Izabel do Prado. Julgamento em primeiro grau: 20 de novembro de 2002. Disponível em: <http://www.cpisp.org.br/acoes/pdf/sentenca_Ivaporunduva.pdf.> Acesso em: 25 jan. 2012.

Ministério do Desenvolvimento Agrário. Quadro Atual da Política de Reconhecimento de Territórios Quilombolas no INCRA, de 14 de junho de 2011. Disponível em: $<$ http://ccr6.pgr.mpf.gov.br/institucional/grupos-de-trabalho/quilombos-1/documentos-1.>. Acesso em: 06 jan. 2011.

Presidência da República (SEPPIR). Perfil das Comunidades Quilombolas: Alcântara, Ivaporunduva e

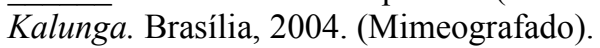

Presidência da República (SEPPIR). Relatório de Gestão do Programa Brasil Quilombola, 2009. Disponível em: http://www.seppir.gov.br/.arquivos/relatorio_gestao_pbq2009. Acesso em: 25 dez. 2011.

Portaria n. ${ }^{\circ}$ 307, de 22 de novembro de 1995 (INCRA). Disponível em: <http://www.cpisp.org.br/htm/leis/fed4.htm.>. Acesso em: 06 nov. 2011.

. Portaria n. ${ }^{\circ} 447$, de 02 de dezembro de 1999. Delega competência à titular da Presidência da Fundação Cultural Palmares. Disponível em: <http://www.cultura.gov.br/site/wp-content/uploads/2007/11/portaria-447de-1999.pdf>. Acesso em: 06 nov. 2011.

. Supremo Tribunal Federal. Mandado de Injunção n. ${ }^{\circ}$ 630. Relator: Min. Joaquim Barbosa. Brasília: 05 dez. 2005. Disponível em: $<$ http://www.stf.jus.br/portal/jurisprudencia/listarJurisprudencia. asp?s1=\%28MI \%24\%2ESCLA \%2E+E+630\%2ENUME\%2E\%29\&base=baseMonocraticas.>. Acesso em: 11 nov. 2011.

. Supremo Tribunal Federal. Ação Direta de Inconstitucionalidade n. ${ }^{\circ}$ 3.239, de 26 de junho de 2004. Relator: Min. Cezar Peluso. Pendente de Julgamento. Disponível em: $<$ http://redir.stf.jus.br/estfvisualizadorpub/jsp/consultarprocessoeletronico/ConsultarProcessoEletronico.jsf? seqobjetoincidente $=2227157>$. Acesso em: 20 maio 2012.

CHASIN, Ana Carolina da Matta. 20 Anos de Regularização Fundiária de Territórios Quilombolas: um balanço da implementação do direito. Revista Política Hoje, vol. 18, n. 2, 2009, p. 158-183.

. A atuação do INCRA e a titulação de territórios quilombolas. Trabalho apresentado no XIV Congresso Brasileiro de Sociologia, realizado em Novembro entre os dias 28 e 31 de julho de 2009 no Rio de Janeiro - RJ. Disponível em: <http://portal.saude.gov.br/portal/arquivos/pdf/Rel_Fin_CPI_TerrasAmazonia_pdf.pdf. $>$. Acesso em: 24 nov. 2011.

COMPARATO, Fábio Konder. Ensaio sobre o juízo de constitucionalidade de políticas públicas. In: Revista de Informação Legislativa. Brasília, a. 35, n. 138, p. 39-48, abr./jun. 1998.

DULITZKY, Ariel E. Cuando los afrodescendentes se transformaran em "pueblos tribales": el sistema interamericano de derechos humanos y las comunidades rurales negras. In: El Outro Derecho, n. 40. Actualidad de las luchas y debates de los afrodescendentes a uma década de Durban: experiencias en America Latina e le Caribe. Bogotá: ILSA, 2010. Disponível em: < http://www.utexas.edu/law/faculty/adulitzky/53-Cuando-Losafrodescendientes-se-transformaran-dn-pueblo-tribales.pdf $>$. Acesso em: 16 jan. 2012.

DUPRAT, Débora (Org.). Pareceres Jurídicos: direito dos povos e comunidades tradicionais. Manaus. UEA, 2007.

FAIDHERB, Sandy Rodrigues. Regularização fundiária de áreas rurais na Amazônia: uma análise da Lei 11.952 de 25 de junho de 2009. Monografia (Graduação) - Curso de Graduação em Direito, UFPA, Belém, 2009. 
108

FRANCO, Rangel Donizete. A desapropriação e a regularização dos territórios quilombolas. Dissertação (Mestrado). Universidade Federal de Goiás: Goiânia, 2012.

FREITAS, Vitor Sousa. Novo constitucionalismo democrático latino-americano: paradigma jurídico emergente em tempos de crise paradigmática. Monografia (Especialização em Direito Constitucional). Curso de PósGraduação em Direito Constitucional da UFG, Goiânia, 2012.

MARTÍNEZ DALMAU, Rubé. Entrevista sobre o Novo Constitucionalismo Democrático Latino Americano.

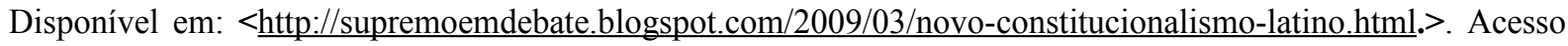
em 16 out. 2011.

HERRERA FLORES, Joaquín. A (re)invenção dos direitos humanos. Trad. Carlos Roberto Diogo Garcia, Antônio Henrique Graciano Suxberger e Jefferson Aparecido Dias. Florianópolis: Fundação Boiteux, 2009.

MEDEIROS, Leonilde Servolo. Dimensões políticas da violência no campo. In: Tempo, Rio de Janeiro, vol. 1, 1996, p. 126-141. 139. Disponível em: http://www.historia.uff.br/tempo/artigos livres/artg1-7.pdf. Acesso em: 23 jan. 2012.

PIOVESAN, Flávia. MIGUEL, Paula Castello; SIQUEIRA, Júlio Pinheiro Faro Homem de; TEIXEIRA, Bruno Costa. Uma homenagem aos 20 anos de Constituição Brasileira. Florianópolis: Boiteux, 2008.

REBELO, Maria de Nazaré de Oliveira. Cadernos da Escola de Direito e Relações Internacionais, Curitiba, 14: 95-118 vol.1.

REIS, Alexandro. As comunidades quilombolas no governo Lula. Disponível em: $<$ http://www.unegro.org.br/arquivos/arquivo 192.pdf. $>$. Acesso em: 10 nov. 2011.

RICOEUR, Paul. O Justo 1: a justiça com regra moral e como instituição. Tradução Ivone C. Benedetti. São Paulo: Martins Fontes, 2008.

ROSA, Alexandre Morais da. Decisão penal: a bricolage de significantes. Rio de Janeiro: Lumen Juris, 2006.

SEN, Amartya. O desenvolvimento como liberdade. Rio de Janeiro: Companhia das Letras, 2010.

SOARES, Aldo Asevedo. Cidadania Kalunga. Dissertação (Mestrado em Direito Agrário) - Pós-Graduação em Direito da Universidade Federal de Goiás, UFG, Goiânia, 1993.

SOUZA FILHO, Carlos Frederico Marés de. O renascer dos povos indígenas para o direito. 5. tir. Curitiba: Juruá, 2006.

Multiculturalismo $\quad e \quad$ Direito Coletivos. Disponível em: $\overline{<\text { http://www.dhnet.org.br/educar/dados/textos/mares multicult.htm. }}$. . Acesso em: 13 fev. 2011.

STEFANINI, Luiz Lima. A propriedade no Direito Agrário. São Paulo: Revista dos Tribunais, 1978.

TARREGA, Maria Cristina Vidotte Blanco. Hermenêutica, narrativa e normatividade: possibilidade de construção do sentido do direito no jurisprudencialismo. Trabalho publicado nos Anais do XIX Encontro Nacional realizado em Fortaleza - CE nos dias 09, 10, 11 e 12 de junho de 2010.

Produção agrícola integrada e desenvolvimento sustentável. In: TARREGA, Maria Cristina Vidotte

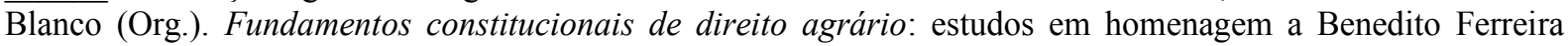
Marques. São Paulo: SRS, 2010.

TRECCANI, Girolamo Domenico. Terras de Quilombo: caminhos e entraves do processo de titulação. Belém: Secretaria Executiva de Justiça. Programa Raízes, 2006.

VICIANO PASTOR, Roberto Alfonso. El derecho de propriedade y la propriedad de la tierra en el Nuevo Constitucionalismo Latinoamericano. In: I Congresso Internacional sobre o Pensamento Jurídico Contemporâneo e XV Jornada Goiana de Filosofia e Teoria do Direito, intitulado "Propriedade e Desenvolvimento: seus direitos e seus sujeitos”. Goiânia: UFG/PUC-GO, ago./ set. 2011.

VIEIRA, José Ribas. Refundar o Estado: o novo constitucionalismo latinoamericano, UFRJ, 2009. Disponível em: <http://pt.scribd.com/doc/24243799/UFRJ-Novo-Constitucionalismo-Latino-Americano>. Acesso em: 17 out. 2011.

WILHELMI, Marco Aparício. Possibilidades y limites del constitucionalismo pluralista: derechos y sujetos em la Constitución ecuatoriana de 2008. In: FARJARDO, Raquel Z. Yrigoyb (Editora). Pueblos indígenas: constituciones y reformas políticas em América Latina: Lima: IIDS, 2010.

Artigo recebido em 25 de maio de 2012 e aceito em 27 de junho de 2012. 